leaned nonchalantly on their rifles, and a priest droned the last rites like a black fly in summer.

No one would come in the final moment with a pardon.

Whatever the man had done would be remembered:

Possibly something as trivial as speaking out of turn.

The man looked around him as though unaware

that sentence had been passed and he would die.

Just before the order was given they led a woman into the courtyard, evidently for a last visit.

We heard her say to him in a high, clear voice,

"If I love you, it is not for anything you have done."

And that was all; in a moment she was gone,

the man was dead, and the troops were marching away.

I don't know why I remember this sequence,

or why it keeps happening over and over, as though

I were somewhere outside myself waiting for it to end,

to become something other than it is, her name

the one word opening like a bullet in his lung.

\title{
The Woman in the Big Boy Restaurant and I / David McElroy
}

I love the way she bites the $O$

of the donut and eats it into a $\mathrm{C}$,

the glazing sugar sprinkling her lap

where a pink package crinkles in the heat.

I want to kiss the curlers in her hair.

I want to flex my biceps,

make payments on her station wagon,

caress her cheek with all the little holes

in it looking like a minute steak.

I want to eat her face.

I want to take my clothes off

and just like a pussy cat in catnip

slither and hiss and squirm and roll all

over her four blond brats. 
I want to give her an expense-paid trip for two.

I want to give her just one good night

on Diamond Head, my sports car reflecting

the glow of the distant surf,

the close pounding of the moon.

Of course I want to unbutton her fuchsia

pedal pushers and tell her it's all right.

I want to look her straight in the eye,

death's little hideout.

And then, then I want to ease her out

of her tiger-striped bikini panties,

and before the anaconda crush of time makes us one,

I want to eat them.

\section{The Temptation to Exist: Overview, Texas / Ira Sadoff}

On a plain in Texas, a landscape barren as morality, a drop of water forms on the cactus leaf. A snake uncoils itself, its many spools of skin. On the rare occasion when a person enters this world, he is dressed in nineteenth-century regalia, lost in this century as the rest of us. And when a car drives past on a dirt road, it kicks up dust, clouds and clouds of dust.

Just before evening, grandmothers begin to appear on the porches. There is tobacco in the air, the vague rumblings of someone's voice. Soon something small and human will occur in the house-mother will drop a dish on the way to the kitchen table, father will push his boot through the door when his daughter disobeys him. Somewhere behind the house a teen-age boy sits with his girl friend on a fence. They invent something to talk about: the virtues of evening, the cactus leaf's odd shape. "I wish I remembered the dust bowl," the girl says, "with all its swirls and swirls." When she lifts the hem of her dress to examine the floral print, the boy wants to say, "How lovely women are," but listens to the radio instead, with its three ugly tunes.

What does he care about the irony of human life, that literary invention. Tonight the world outside seems small: the stars are shriveled seeds, the hum of the locusts and the junebugs so familiar they cannot be heard. When he lights a cigarette and the girl sighs, a few cinders from his hand move toward the sky-and in that light, in the bright hiss of a match, they appear 